\title{
NUEVOS DATOS PARA LA BIOGRAFÍA DE JUAN DE OCHOA, MAESTRO CANTERO CORDOBÉS DEL QUINIENTOS
}

\author{
Juan Luque Carrillo \\ Universidad de Córdoba \\ juanluque317@gmail.com
}

\section{Resumen}

Juan de Ochoa Méndez fue un destacado arquitecto cordobés de la segunda mitad del siglo xvi. Su impronta y su particular lenguaje constructivo se adscriben dentro de la corriente clasicista española de finales del Quinientos, a la maniera italiana, que depuró la tradición renacentista y sentó las bases del futuro estilo barroco durante los primeros ańos del siglo xvir. Su prolífica trayectoria profesional al servicio de las principales instituciones religiosas y civiles de la Córdoba del momento ha sido recientemente reconstruida gracias a las numerosas referencias y datos documentales extraídos de los principales archivos cordobeses, particularmente del Histórico Provincial.

Palabras clave: Juan de Ochoa, arquitectura del Renacimiento, cantería, siglo xvi, Córdoba.

\author{
NEW DATA FOR THE BIOGRAPHY OF JUAN DE OCHOA, \\ CORDOVAN STONEWORK MASTER OF THE $16^{\mathrm{TH}}$ CENTURY
}

Abstract

Juan de Ochoa Méndez was a prominent Cordovan architect who worked in the second half of the $16^{\text {th }}$ Century. His style and particular constructive language fall within the Spanish classicist current of the late $1500 \mathrm{~s}$, according to the maniera italiana, which refined the Renaissance tradition and set the foundations for the future baroque style during the first years of the $17^{\text {th }}$ Century. His prolific professional career at the service of the main religious and civil institutions of Córdoba at the time, has recently been reconstructed thanks to the numerous references and documentary data extracted from the main Cordovan archives and particularly the Historical-Provincial Archive.

KeYwords: Juan de Ochoa, Renaissance architecture, stonework, $16^{\text {th }}$ Century, Córdoba. 


\section{INTRODUCCIÓN}

Una de las figuras más sobresalientes de la arquitectura cordobesa del siglo Xvi es Juan de Ochoa. Su personalidad artística está ligada a la corriente clasicista de influencia italiana que, en el contexto de la Andalucía Occidental, tuvo una especial proyección durante las décadas finales de la centuria, particularmente en el ámbito religioso y en algunas construcciones - públicas y privadas- patrocinadas por las principales élites sociales e instituciones civiles. Su proyección arquitectónica, sin embargo, ha sido revisada recientemente y narrada en el trabajo El arquitecto Juan de Ochoa. 1554-1606 (Luque 2020), donde se ofrece la biografía del personaje y un catálogo de su obra, tanto religiosa como civil, fruto de la labor de vaciado documental en los principales archivos de la ciudad, donde se han encontrado numerosas referencias y datos de particular interés.

Estimulado por las corrientes humanistas de mediados del siglo XVI, este maestro aseguró la continuación de los talleres de cantería existentes desde el final de la Edad Media en Córdoba, renovados ahora oportunamente con nuevos elementos formales y soluciones constructivas que marcaron el cambio definitivo de la anterior tradición arquitectónica medieval a las nuevas propuestas modernas. Su vida y su trayectoria profesional pueden considerarse un reflejo del característico modus vivendi de la mayoría de los maestros canteros que protagonizaron la transición del arte del Quinientos al del siglo xviI, con una particular participación en el ámbito religioso, si bien en la actualidad gran parte de su producción ha desaparecido a consecuencia de las abundantes reformas en los templos durante los últimos siglos, o bien sus destrucciones totales cuando las exigencias diocesanas lo estimaron necesario.

El objetivo de este artículo es sintetizar todas las aportaciones recientemente descubiertas para facilitar el conocimiento del arquitecto, incluyendo algunos datos novedosos que completan su perfil tanto humano como profesional, y rectificar ciertos errores historiográficos planteados en la bibliografía de finales del siglo pasado.

\section{NOTICIAS DE LA INFANCIA}

Juan de Ochoa nació en Córdoba en 1554 en el seno de una familia ligada al arte de la cantería. Sus padres eran Martín de Ochoa, cantero de profesión, y Ana Méndez. Su bautizo se celebró el día 27 de diciembre del mismo año en la parroquia de El Sagrario de la catedral cordobesa, siendo apadrinado por los canónigos Melchor de Pineda y Cristóbal de Mesa, y por las religiosas María y Francisca de Valenzuela, que vivían en la casa-beaterio del Espíritu Santo, origen del futuro convento de dominicas del Corpus Christi ${ }^{1}$.

${ }^{1}$ Partida bautismal de Juan de Ochoa, 27 de diciembre de 1554, Archivo de la Parroquia de El Sagrario, Córdoba (APSC), Libro I de Bautismos, Tomo III, fol. 149 vto. 
Cuando Juan nació, su familia llevaba años residiendo en la collación de Santa María, en la calle Santa Quiteria (actual Judíos), cerca del hospital del mismo nombre fundado en el siglo xv para atender a enfermos hidrófobos. Durante toda su infancia, el pequeño Juan estuvo en contacto directo con las obras y proyectos de nueva fábrica en la catedral, donde su padre compaginaba sus labores de maestro cantero al servicio del consistorio e instituciones civiles con las de conservación y mantenimiento del templo, por petición del obispo don Diego de Álava y Esquivel (1558-1562) (Gómez 1778). Este contacto diario con la catedral despertó en el crío una decidida inclinación hacia el mundo de las artes, y en concreto hacia la arquitectura, especializándose desde muy joven en la tradición cantera local y conocimientos sobre arquitectura clásica.

Dos años después del nacimiento de Juan vino al mundo el siguiente hijo del matrimonio Ochoa-Méndez: Leonardo, también bautizado en la misma parroquia de El Sagrario el día 10 de noviembre de 1556, apadrinado por los canónigos Juan de Clavijo y José de Mohedano, y de nuevo las religiosas Francisca y María de Valenzuela ${ }^{2}$.

Más adelante la familia se trasladó a la collación de Omnium Sanctorum, donde nacieron los restantes tres hijos: Andrés en 1567, Jerónimo en 1569 e Isabel, cuyos hallazgos documentales sitúan la fecha de su nacimiento entre 1570 y 1572. Ningún hijo varón del matrimonio había mostrado especial interés por seguir la profesión paterna, salvo Juan, lo que debió producir en Martín una impresión honda y grata a la vez. Movido por este especial entusiasmo, el cantero puso de su parte todos los medios necesarios para que el muchacho recibiera una adecuada y completa educación artística, con suficiente experiencia teórica y práctica, y una profunda formación en el campo de la ingeniería, que era la categoría social más alta en el mundo de la construcción (Villar 1986).

Aunque las primeras enseńanzas corrieron a cargo del padre, era preciso buscar un referente de mayor prestigio para asegurar la sólida y eficaz formación del joven aspirante; un conocido maestro en la profesión con el que ampliar los conocimientos necesarios y asegurar el triunfo en el oficio. El futuro arquitecto parecía más atraído por los trabajos de ingeniería en casos relacionados con la hidráulica, al menos en una primera fase donde intervino en varios proyectos de conducciones de aguas, reconstrucciones de puentes, azudas, pozos y diseños de fuentes.

En esos años, Córdoba contaba afortunadamente con una figura de gran relieve en este campo de especialización: Hernán Ruiz III (1534-1606), reconocido maestro que falleció en circunstancias desconocidas cuando precisamente se hallaba en la localidad gaditana de Arcos de la Frontera, dando las trazas de un puente en cantería sobre el río Guadalete (Camacho 1986).

2 Partida bautismal de Leonardo de Ochoa, 10 de noviembre de 1556, APSC, Libro I de Bautismos, Tomo III, fol. 211 vto. 
Aunque no hemos localizado la carta de aprendizaje de Ochoa en los protocolos notariales del Archivo Histórico-Provincial de Córdoba, es muy probable que esta educación artística la llevara a cabo junto a Hernán Ruiz III. Martín de Ochoa, que no había trabajado en proyectos de ingeniería y carecía de los conocimientos esenciales de esta especialidad, asumió únicamente la maestría del hijo en un primer momento, reservando el grueso de la formación a aquel maestro que supiera inculcar en el joven los conocimientos plenos y una dilatada experiencia en la profesión. La elección de Hernán Ruiz III no debió ser de ningún modo arbitraria, pues, a pesar de ser vecinos en la misma collación, deben tenerse en cuenta otras circunstancias que dieron a este supuesto aprendizaje un cariz especial: las relaciones afectivas entre ambas familias, traducidas en el matrimonio entre Juan de Ochoa y una de las hermanas de Hernán Ruiz III (Morales 1996).

El testamento de Martín de Ochoa, otorgado en 1573, menciona en varias cláusulas una serie de trabajos contratados en mancomunidad con Hernán Ruiz III, lo que parece indicar una posible amistad entre ambos canteros o, en cualquier caso, una buena relación entre compañeros de profesión. Por lo tanto, es muy probable que la primera esposa de Juan de Ochoa sea la misma María de Gibaja, hermana de Hernán Ruiz III, con la que tuvo a sus dos primeros hijos: Francisca y Luis. Parece clara esa relación basada a priori en relaciones profesionales y más adelante manifestada también en el terreno personal, aspectos que solían aunarse con bastante frecuencia en el contexto socioartístico de la época.

Durante los primeros años de la década de 1570, el joven Ochoa completó su formación teórica gracias al estudio de la geometría y, en especial, con la lectura de los tratados de Diego de Sagredo (primera edición de Toledo, 1526), Serlio (Toledo, 1552), Alberti (Madrid, 1552) y particularmente de Hernán Ruiz II -a través de Hernán Ruiz III-, de quien aprendió modelos y trazas, adiestrándose hábilmente en el dibujo y la composición como pasos imprescindibles del diseño (Valverde 1970).

Guiado, pues, por las instrucciones paternales y enseñanzas de Hernán Ruiz III, Juan de Ochoa empezó a trabajar como maestro albañil aún sin haberse presentado a la prueba de examen que le permitiría oficialmente ejercer el oficio de cantero. De la mano de su padre, comenzó a contratar obras muy concretas sin pertenecer a la nómina de ninguna institución, como sí ocurrirá en el futuro. Así es citado el 7 de abril de 1573 en la escritura extendida ante Rui Pérez, notario, en la que fio a su padre y a Fernando de Zabala la reconstrucción del puente que unía los pueblos de Pontón don Gonzalo y Mira Genil, y que hoy, unidos en uno solo, se conocen por Puente Genil (Banda 1974).

Sin embargo, la referencia más antigua que de él poseemos, aparte de las citas en la partida bautismal y testamento materno, se encuentra en el documento firmado por el escribano Melchor de Córdoba el 18 de diciembre de 1570, en el que concertó con los canteros Pedro de Sosa y Alonso Gómez cuatrocientas carretadas de piedra blanca procedentes de la cantera de El Lanchar, en Cabra, para las 
obras del desaparecido claustro del monasterio de San $\mathrm{Pablo}^{3}$, fundado en el siglo XIII sobre los cimientos de un palacio almohade fechado en $1135^{4}$.

Otros de los primeros trabajos de Ochoa, previos a su incorporación oficial al gremio del alarifazgo cordobés, fueron la capilla mayor y reja de la desaparecida parroquia de San Juan, en la collación del mismo nombre, y la reparación del pozo, alberca y noria de don Pedro Ruiz de Valencia, en la finca de Cercadilla, en el ensanche nororiental de la ciudad, ambas obras contratadas en mancomunidad entre 1571 y 1574 con Martín Ruiz Ordónez, cantero, hermano también de Hernán Ruiz III, con quien compartió otros encargos, la mayoría religiosos, a partir de 1579 (Rosas 2003).

\section{EL EXAMEN DE CANTERO}

Concluidos estos primeros trabajos, Juan de Ochoa preparó su examen para entrar a formar parte del gremio de alarifes y maestros canteros de la ciudad de Córdoba y, tan solo con 20 años, conforme a los usos y costumbres de la época, fue examinado en sesión celebrada el 22 de junio de 1574 por los diputados Diego Ruiz Cantillo y Pedro de la Cruz. La prueba se realizó en presencia de estos dos veedores del gremio, más un teniente de asistente de la ciudad, Pedro Suárez, y el notario Luis Núnez de Toledo, que redactó el documento notarial's.

$\mathrm{El}$ joven expuso ante los examinadores que

avia aprendido y sabia el oficio de albańyleria para poder ser maestro del dicho oficio y que a ellos les constava dello por que se lo avian visto usar y por ello pedia que lo viesen por maestro como es cumplido y le diesen licencia y facultad para que como tal maestro pudiese usar el dicho oficio $[\ldots]^{6}$.

El veredicto del jurado trajo consigo la superación de la prueba con éxito, obteniendo la licencia necesaria para ejercer, por tanto, el oficio en todas sus ramas y campos de especialización.

${ }_{3}$ Escritura otorgada por Pedro de Sosa y Alonso Gómez, canteros, concertando con Juan de Ochoa 400 carretadas de piedra para las obras del claustro del monasterio de San Pablo de Córdoba, 18 de diciembre de 1570, Archivo Histórico-Provincial de Córdoba (AHPC), Protocolos Notariales, 15314-P, fol. 574 r.

${ }^{4}$ Esta obra fue destruida en el siglo XIX, conservándose en la actualidad únicamente un fragmento de arcada en la panda occidental del patio de la actual Delegación Provincial de Cultura de la Junta de Andalucía.

${ }^{5}$ Carta de examen del maestro cantero Juan de Ochoa, otorgada por Diego Ruiz Cantillo y Pedro Sánchez de la Cruz, alarifes de Córdoba, 22 de junio de 1574, AHPC, Protocolos Notariales, 16751-P, fol. 395 r. y vto.

${ }^{6}$ Carta de examen del maestro cantero Juan de Ochoa, otorgada por Diego Ruiz Cantillo y Pedro Sánchez de la Cruz, alarifes de Córdoba, 22 de junio de 1574, AHPC, Protocolos Notariales, 16751-P, fol. 395 r. y vto. 


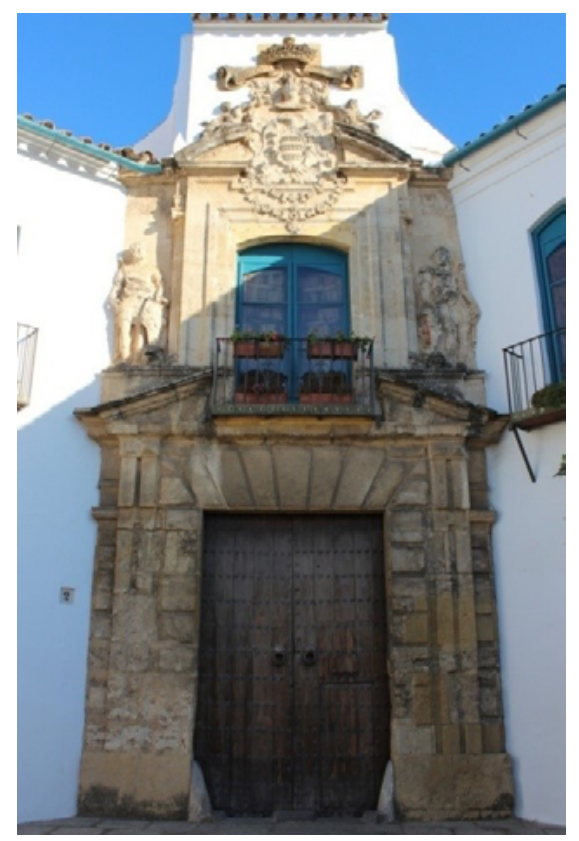

Fig. 1. Portada de las casas principales de don Luis Gómez de Figueroa, actual Palacio de Viana, Córdoba. Juan de Ochoa, 1576. Fotografía del autor.

Conseguido el permiso, Juan de Ochoa comenzó a practicarlo con independencia de los maestros con los que trabajó durante sus primeros años, aunque sin dejar de colaborar con su padre y sin abandonar las obras contratadas en los meses precedentes, lo cual le permitió seguir experimentando en la profesión hasta completar su formación y definir su particular lenguaje arquitectónico.

La primera gran obra contratada por Ochoa tras la aprobación del examen fue la portada principal de las casas solariegas de la familia Gómez de Figueroa, en el barrio de Santa Marina, proyecto financiado por don Luis Gómez de Figueroa, II señor de Villaseca, por el precio de 1500 reales$^{7}$. Esta magnífica portada fue proyectada en el ángulo suroccidental del patio principal, el de recibo, y se encuentra encajada entre dos crujías convergentes sobre un mismo plano, apreciándose en su diseño influencias tanto de Francisco del Castillo (en el tipo de pórtico) como de Hernán Ruiz II (en las columnas empotradas que flanquean la arquitectura del balcón) (Moreno 2009). Finalizada en julio de 1576, se trata de una de las obras

7 Escritura de concierto entre don Luis Gómez de Figueroa y Juan de Ochoa para la ejecución de la portada del recibo en las casas principales del mayorazgo, 23 de mayo de 1576, AHPC, Protocolos Notariales, 9266-P, fols. 142-143. 


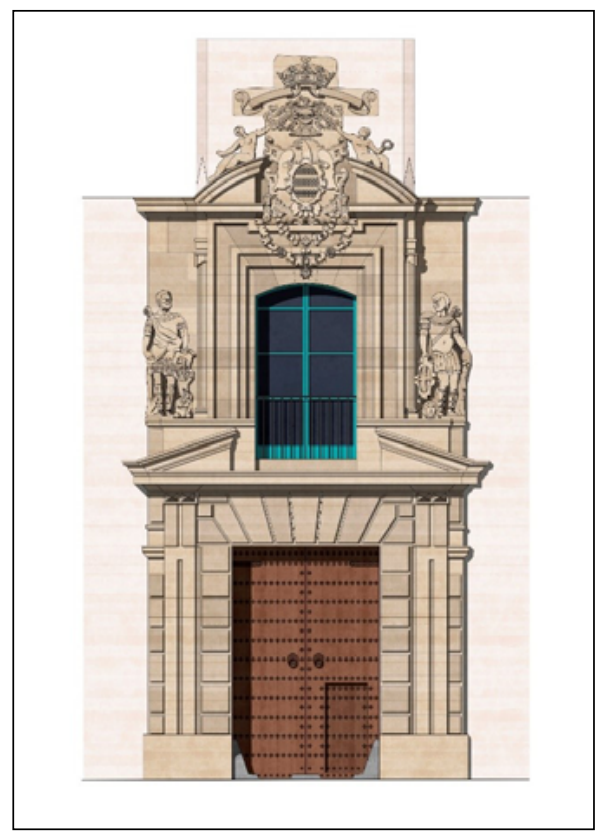

Fig. 2. Portada de las casas principales de don Luis Gómez de Figueroa, actual Palacio de Viana, Córdoba. Juan de Ochoa, 1576. Autor del dibujo: Imanol Iparraguirre.

más relevantes y corporativas de la arquitectura civil cordobesa del último tercio del Quinientos, tradicionalmente atribuida al maestro y ahora, tras la reciente revisión documental, confirmada su autoría y el contexto en que se ejecutó (figs. 1 y 2).

Con esta excepcional muestra arquitectónica concluye el periodo de formación y juventud del maestro. En esta etapa inicial de su producción hemos considerado las obras realizadas antes de 1577; es decir, algunos trabajos de ingeniería hidráulica y sus primeros contactos con las arquitecturas civil-residencial y religiosa. Es el momento en que el artista fija, aun con ciertas dudas, su estilo, fluctuando entre las enseñanzas de sus dos grandes maestros: su padre y Hernán Ruiz III. Sin embargo, a partir de 1574 aparecen en sus obras los rasgos más característicos que definieron su lenguaje constructivo, tanto en el diseño de espacios como en las expresiones decorativas, preludiándose las grandes creaciones del periodo de madurez (Luque 2020).

\section{LA SOMBRA DE LA MUERTE}

Por entonces el joven arquitecto estaba a punto de cumplir los 24 ańos, edad adecuada para contraer matrimonio y formar su propia familia. Sus hermanos Leonardo, Andrés y Jerónimo habían fallecido y toda la atención de los padres giraba en torno a la pequeña Isabel, menor de edad. Además, su posición laboral y económica 
comenzaba a ser cada vez más estable, y su juventud y espíritu ambicioso eran claros síntomas de una decidida personalidad que terminaría premiándole con numerosas recompensas profesionales. Por consiguiente, piensa que ha llegado el momento de independizarse y constituir su propio hogar.

Su esposa fue la cordobesa María de Gibaja, de la que no hemos localizado carta dotal en los protocolos cordobeses, ni partida matrimonial en los archivos parroquiales de la ciudad. Como ya se ha explicado, el nombre de la joven relaciona al arquitecto con la dinastía Hernán Ruiz, al tratarse con total probabilidad de la misma María de Gibaja hija de Hernán Ruiz II y Luisa Díaz, como ya planteó la historiadora Esperanza Rosas tras hallar el testamento de Hernán Ruiz II, donde el arquitecto cita a sus herederos legítimos, entre ellos María de Gibaja, su hija pequeña, quien quedaba bajo tutela de su esposa y primogénito, Hernán Ruiz III (Rosas 2003).

Fueron años en que Ochoa contrató con Hernán Ruiz III varias obras en mancomunidad, e indudablemente las relaciones entre ambos maestros debieron ser frecuentes y directas. Por tanto, Ochoa conoció de primera mano la situación familiar de la joven Gibaja, sobre la cual recaía el peso de ser hija de Hernán Ruiz II, consideración muy valorada y tenida en cuenta seguramente por el maestro a la hora de iniciar una relación sentimental.

El propio contexto familiar puede confirmar la hipótesis planteada, pues tanto Luisa como Catalina, las hijas mayores del matrimonio Ruiz Díaz, contrajeron años antes matrimonio con otros artistas de la época; la primera con el avilés Jerónimo Hernández (1540-1586) y la segunda con el jienense Andrés de Ocampo (1555-1623), lo que hace pensar que la hija menor también se emparentara con algún artista de la época, siguiendo el ejemplo de sus hermanas mayores.

Pero fuese o no hija de Hernán Ruiz II, lo cierto es que Ochoa contrajo matrimonio con ella entre 1577 y 1579, estableciéndose en la collación de Omnium Sactorum, en cuya parroquia fue bautizada su hija Francisca el día 7 de febrero de 1580, siendo apadrinada por don Luis Gómez de Figueroa, al que ya nos hemos referido anteriormente, y su esposa, doña Ana de Argote ${ }^{8}$. Años después debió nacer el segundo hijo del matrimonio: Luis, del que no hemos hallado la partida bautismal, pero del cual sabemos que profesó en el monasterio de la Santísima Trinidad de la ciudad en 1600, de manos del padre Luis de Luna, ministro de la comunidad (Olmedo 2012).

Paralelamente las relaciones sociales del arquitecto en estos años, y aun después, se redujeron esencialmente a las propias del gremio, salvo algún caso excepcional, según se desprende de sus intervenciones en obras muy concretas, ampliando su listado de promotores y mecenas a medida que avanzaba la centuria. En consecuencia, desde este momento, y hasta su muerte en 1606, resulta fácil seguir su trayectoria profesional, dadas las abundantes noticias que de él poseemos, aparte de considerar que seguramente sus intervenciones debieron ser

8 Partida bautismal de Francisca de Ochoa, 7 de febrero de 1580, Archivo de la Parroquia de San Juan y Todos Los Santos, Córdoba (APSJTSC), Libro II de Bautismos, fol. 10 vto. 
aún mucho más abundantes, aunque carezcamos de datos concretos sobre ellas (Galera 2011).

Sin embargo, esta feliz vida familiar quedó bruscamente interrumpida a causa de la muerte de Gibaja, probablemente víctima de la epidemia de peste que asoló gran parte de la ciudad en 1589, poniendo fin a los casi diez años de vida en común de la pareja. También este brote epidémico causó el fallecimiento de Francisca, provocando en Juan de Ochoa un gran vacío y dolor ante tales dolorosas pérdidas.

Acuciado por los tristes acontecimientos familiares, el maestro no tardó en descubrir cuál iba a ser su futuro camino y, decidido a rehacer su vida, hubo de recuperarse y abrir nuevos horizontes. Fueron años difíciles para la ciudad, como consecuencia de la elevada tasa de mortalidad y las duras recesiones en el marco económico. Los abundantes repuntes de peste habían destrozado barrios enteros -el de Omnium Sanctorum fue precisamente uno de los más afectados-, y habían envuelto a sus habitantes en una atmósfera de tristeza y desesperanza generalizada. En un breve espacio de tiempo, el artista vio morir a cuatro de sus hermanos, a su esposa, hija y amigos. La conmoción, el miedo y la sensación de soledad que las trágicas circunstancias trajeron consigo para la mayor parte de los cordobeses debieron influir poderosamente, hasta el punto de decidir contraer nuevamente matrimonio y abandonar, por tanto, aquel estado de debilidad emocional (Luque 2017b).

La joven elegida esta vez fue la cordobesa Francisca de Paula y, al igual que Gibaja, no sabemos qué aportó de dote al matrimonio, ni en qué fecha exacta tuvo lugar el casamiento. Pensamos, ante todo, que el enlace debió celebrarse en la parroquia de Omnium Sactorum, barrio donde residía el artista desde su anterior matrimonio y en el que permaneció hasta su fin, según consta en su testamento y en todas las escrituras de contratos de obras.

De este modo Ochoa creó junto a Francisca un nuevo hogar familiar, donde debió reinar la felicidad y el compromiso conyugal, abriéndose para el maestro una nueva y esperanzadora etapa personal. Sin embargo, el inicio de la década de 1590 le iba a deparar una de las pruebas más difíciles de su vida, la más crítica sin duda: el fallecimiento de su segunda esposa, casi al inicio de su nueva andadura matrimonial. Desconocemos el motivo de la muerte de Paula, aunque es muy probable que muriera siendo víctima de algún otro azote de peste durante los años 1590 y 1592. Se inicia entonces otra triste etapa en la vida de Ochoa, en la que nuevamente experimentó una angustia existencial únicamente solazada por sus trabajos y compromisos profesionales. El matrimonio había durado apenas un año y algunos meses, viéndose privados de la oportunidad de ser padres.

La presencia de Francisca de Paula fue como un fugaz destello, pero la huella dejada en el artista debió ser, sin duda, profunda. No obstante, Ochoa debía cerrar sus contratos de trabajo y abrir nuevos caminos profesionales, amparado por el afecto y respaldo económico de su gran amigo y mecenas don Luis Gómez de Figueroa (Espejo 1986). Únicamente sus preocupaciones laborales y la dedicación al trabajo debieron convertirse en su principal vía de escape emocional. Sin embargo, pasado un tiempo prudencial, los acontecimientos se encargaron de dar un nuevo 


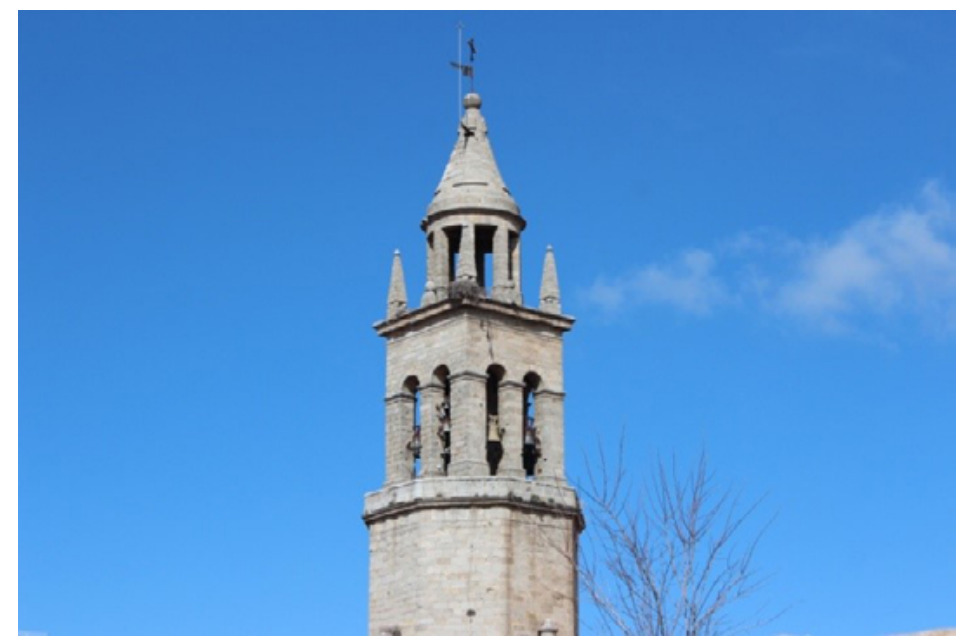

Fig. 3. Torre parroquial de El Salvador, Pedroche, Córdoba. Último cuerpo y chapitel de Juan de Ochoa, 1588. Fotografía del autor.

y profundo giro a la vida del artista: un tercer y último matrimonio con el que por fin logró la estabilidad familiar hasta el fin de sus días.

\section{5. ÚLTIMAS NUPCIAS: MARÍA DE CLAVIJO}

Los ańos que median entre 1589 y 1593 debieron ser para el maestro una etapa de resurgimiento personal y de formación tanto humana como profesional, al servicio de las obras del concejo municipal, junto a los maestros locales de la Córdoba de finales del xvi que constituyeron, indudablemente, su círculo de amigos. Pero en 1593 habrá un giro esencial en su vida: su profesión había alcanzado el mayor grado de proyección artística y sus relaciones sociales eran cada vez más numerosas. Ochoa inició, pues, una nueva andadura marcada por dos acontecimientos personales muy significativos: un tercer y definitivo matrimonio y el nacimiento y defunción de su hija Elvira.

Recuperado de la pérdida de su segunda esposa, Juan de Ochoa decidió contraer matrimonio de nuevo. La mujer elegida fue una joven de veinte años llamada María de Clavijo Daza, hija de un mercader de telas ya difunto, llamado Rodrigo Alonso de Clavijo, y de Elvira Daza, que fue quien otorgó al artista la carta dotal de su hija el 11 de enero de 1595. En este documento Ochoa aparece citado como "maestro mayor de las obras de la ciudad de Cordova» y se dice "vecino de Omnium Sactorum». La dote en cuestión -muebles, ropas y joyas especialmente-, ascendió a 80914 maravedíes, de los cuales 38050 les fueron entregados en metálico. Por su 
parte, el maestro declaró haber entregado a su esposa en cantidad de arras, 32864 maravedíes?.

Los esponsales de Ochoa -a la sazón de 39 años- y María de Clavijo se celebraron en la parroquia de Omnium Sanctorum el día 14 de octubre de 1593 y, curiosamente, entre los testigos de la ceremonia no firmó ningún miembro de la familia del $\operatorname{artista}^{10}$.

La nueva pareja se instaló en la vivienda del maestro, en la plazuela frente a las viviendas principales de don Luis de Galicia, en la referida collación de Omnium Sanctorum, en cuya parroquia fue bautizada un año después Elvira, la única hija del matrimonio. Nuevamente encontramos al ilustre caballero don Luis Gómez de Figueroa actuando de padrino en la ceremonia del bautizo, celebrada el 8 de marzo de $1594^{11}$. Nuevamente, la pequeña debió morir de manera prematura, durante sus primeros diez años de vida, con total probabilidad víctima de algún brote epidémico. En el testamento del artista, otorgado el 1 de octubre de 1606, no figura como heredera.

La personalidad de la nueva esposa de Juan de Ochoa apenas si se deja sentir a lo largo de estos años; ella permanece siempre a la sombra, ayudando, animando a su esposo, pero sin ser nunca protagonista. De hecho, se muestra como la excelente compañera, afectuosa y comprensiva que, a su muerte, supo ejecutar las deudas del difunto marido y velar por la salud de su anciana suegra, según manifestó el propio Ochoa antes de morir.

Deducimos, pues, que las relaciones entre Juan y María debieron ser armónicas, cordiales, y estuvieron sazonadas con la permanente presencia de la madre del maestro. Ambos cónyuges revelan una evidente elegancia espiritual, una profunda religiosidad: los dos apoyaron el noviciado del joven Luis, solicitando además ser sepultados en la cripta de la iglesia conventual trinitaria.

Fueron años de gran actividad para Ochoa. Además de los grandes encargos de la capital, el maestro fue solicitado también fuera de ella, en pueblos de la provincia como Hinojosa del Duque, Pedroche, Montemayor o Santaella, donde trabajó en diversos proyectos patrocinados por el Obispado (Nieto 1986), entre los cuales merecen especial mención los cerramientos de las torres parroquiales de las dos primeras localidades (fig. 3). Pero también intervino en obras fuera de Córdoba, caso de Écija y Estepa, ambos municipios pertenecientes a la provincia de Sevilla. Para el primero diseñó en 1583 la planta y modelo de la desaparecida Fuente de las Ninfas que presidió la plaza de España hasta 1866, además de otros trabajos de conducción de aguas, arcas y algunas fuentes más en las principales plazas del pueblo (García 1989). Años después, en Estepa, dio las trazas de la desaparecida iglesia

9 Carta dotal de Juan de Ochoa a favor de María de Clavijo, 11 de enero de 1595, AHPC, Protocolos Notariales, 12417-P, fols. 60-62.

${ }_{10}$ Partida de Matrimonio de Juan de Ochoa y María de Clavijo, 14 de octubre de 1593, APSJTSC, Libro I de matrimonios, fol. 228.

${ }^{11}$ Partida de bautismo de Elvira de Ochoa, 8 de marzo de 1594, APSJTSC, Libro II de Bautismos, fol. 137 vto. 


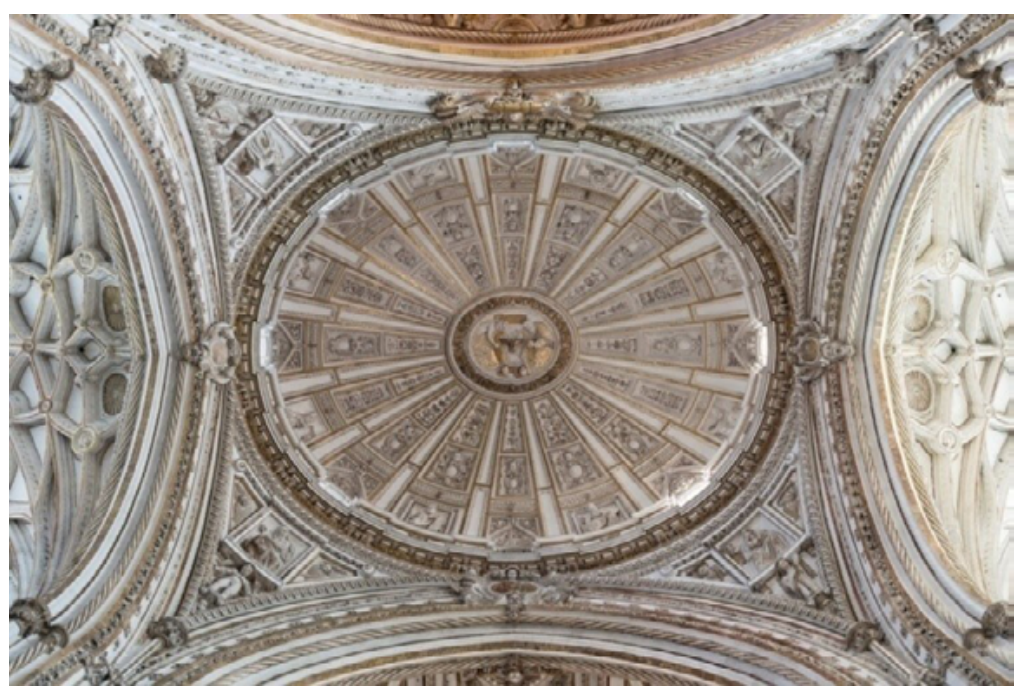

Fig. 4. Bóveda del crucero de la catedral de Córdoba. Juan de Ochoa (arquitecto) y Francisco Gutiérrez (maestro estuquista). 1599-1602.

Fuente: Archivo Catedral Córdoba. Colección fotográfica.

del convento de Nuestra Señora de la Victoria, de la cual solo se conserva -aunque muy intervenida- la fastuosa torre barroca del siglo XviII.

Paralelamente, el maestro completó el cierre del crucero y coro de la catedral de Córdoba en los últimos años de la centuria, según criterio artístico del maestro vallisoletano Diego de Praves, quien viajó a Córdoba en 1598 por petición del obispo don Francisco de Reinoso (1597-1601) (Gómez 1778), para estudiar el modo de cubrir ambos espacios y definir el tipo de cubierta adecuada. Junto a ellos, completó la obra de ornamentación en estucos el maestro antequerano Francisco Gutiérrez Garrido, terminándose definitivamente el proyecto en mayo de 1602 (Luque 2017a) (fig. 4).

Lógicamente, algunos de los trabajos en pueblos de la Diócesis exigieron de Ochoa el desplazamiento hacia el lugar de trabajo, e incluso la obligada residencia temporal por cuestiones de dirección mayor. Seguramente, Clavijo no acompañó a su marido en este tipo de viajes profesionales, pues no parece que las estancias de Ochoa fuera de Córdoba fuesen en exceso largas.

Es muy probable que la juventud de María ayudara al maestro a superar la profunda crisis emocional arrastrada desde el fallecimiento de su primera esposa. Además, la ocupación laboral y la entrega diaria a su trabajo debieron constituir otro importante factor para superar aquel terrible episodio emocional. Por tanto, estos años de feliz vida matrimonial transcurrieron en apacible y tranquila armonía, alternando los trabajos eventuales con el gran proyecto de terminación de la fábrica del crucero y coro catedralicios con el que cerraría, sin duda, el destacado capítulo de la arquitectura del siglo XVI en la ciudad de Córdoba (Villar 1986). 


\section{TESTAMENTO Y FALLECIMIENTO DEL ARTISTA}

Las circunstancias familiares y pérdidas de seres queridos significaron un fuerte golpe emocional para Juan de Ochoa, motivo por el que su salud, quizá quebrantada por alguna enfermedad, experimentó a partir de 1605 un profundo mal del que no logró reponerse.

Durante los años 1604 a 1606 habrá dos asuntos que centraron toda la atención del maestro: la cubrición y posterior ornamentación de la capilla mayor de la parroquia de Santaella y la redacción de su testamento. En el plano profesional, el artista había centrado su interés y últimas energías en dicha fábrica santaellense, que podría considerarse un testamento artístico, aunque no lograra verla terminada (fig. 5), mientras que en el terreno personal desconocemos si sufrió alguna enfermedad, o si la muerte le sobrevino inesperadamente. El hecho de firmar un contrato de obra cuatro meses antes de fallecer parece indicar que al menos por entonces gozaba de salud suficiente como para embarcarse en obras que exigían de él un pleno rendimiento.

Por consiguiente, pensamos que en los últimos días de septiembre de 1606 Ochoa debió enfermar de gravedad y, a principios del mes siguiente, decidió hacer declaración testada ante el notario Francisco Martínez de Molina. Su estado de salud cuando testó era ya crítico, puesto que afirmaba hallarse enfermo de gravedad, hasta el punto de encontrarse impedido físicamente y no poder firmar el documento.

El testamento se otorgó el día 1 de octubre de 1606 y en él, tras las usuales fórmulas de ofrecimiento a Dios, el maestro pidió ser enterrado en el convento de la Santísima Trinidad, donde había profesado su hijo Luis, en la sepultura que el prior y los frailes le cedieran para tal fin ${ }^{12}$. A pesar de ser un personaje relativamente popular, su ánimo creció lejos del deseo de la ostentación y, por ello, se centró en la liberación y perdón de su alma, ordenando para el día del entierro una misa de réquiem cantada, con vigilia y responso (fig. 6).

Asimismo, encargó que se le dijeran 100 misas rezadas, más otras 12 de cíngulo, celebradas en la capilla de los Obispos de la Catedral. También ordenó 20 misas por las almas de su padre, y otras tantas por María de Gibaja y Francisca de Paula, sus difuntas esposas. Seguidamente destinó un real «a la obra de Omnium Sanctorum de reberencia de los santos sacramentos rrecibidos [...] y quatro rreales para los niños espositos $[\ldots]{ }^{13}$. Después de estas disposiciones de tipo espiritual, el maestro indicó la morada donde residió junto a su esposa, en la plazuela de don Luis de Godoy, «a la entrada de la calleja sin salida al fondo de las casas de don Luys [...]». Esta vivienda la tenía arrendada de por vida, con un cargo de 16 ducados anuales que debía entregar a don Rodrigo Alonso de Gahete, propietario del inmueble,

12 Testamento de Juan de Ochoa, 1 de octubre de 1606, AHPC, Protocolos Notariales, 14774-P, fols. 908-912 vto.

13 Testamento de Juan de Ochoa, 1 de octubre de 1606, AHPC, Protocolos Notariales, 14774-P, fols. 908-912 vto. 


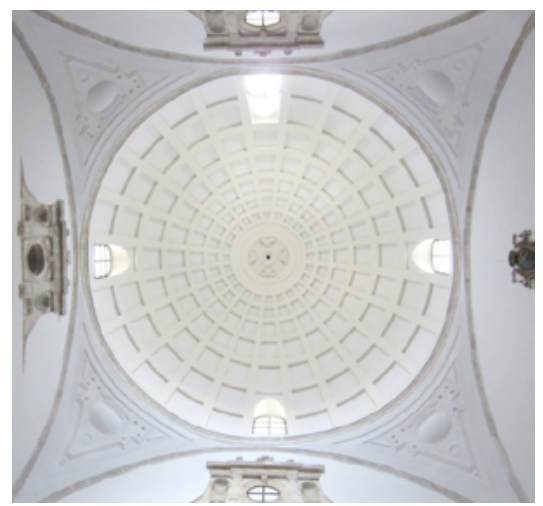

Fig. 5. Cúpula de la capilla mayor de la parroquia de Nuestra Señora de la Asunción, Santaella, Córdoba. Juan de Ochoa, 1604-1606. Fotografía del autor.

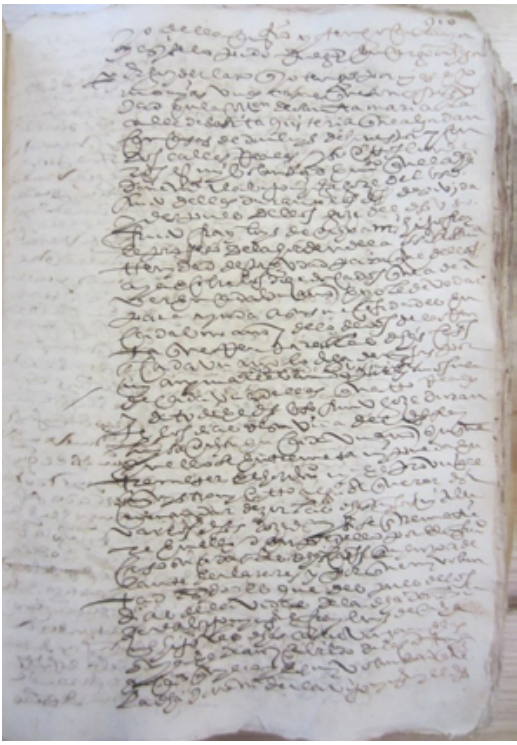

Fig. 6. Testamento de Juan de Ochoa. Archivo Histórico Provincial de Córdoba. Protocolos Notariales, 14774-P, fol. 910. Fotografía del autor.

según contrato de arrendamiento otorgado el 5 de septiembre de 1577 por Alonso Rodríguez de la Cruz, notario público.

Declara entonces que tiene solo un hijo, Luis, «fraile de la orden de la Santisima Trinydad de la ciudad", a quien destina un tercio de su herencia para disfrute personal, y el resto a la viuda, a quien nombra por tanto heredera universal. 
De igual modo, dice ser propietario de unas casas en la collación de Santa María, las mismas donde nació y vivió durante su infancia. Esta vivienda finalmente fue adquirida por la comunidad religiosa trinitaria -a través de fray Luis-, a pesar de la negativa expresa del arquitecto en su documento de últimas voluntades. La desaparición de los frailes en el siglo XIX dio lugar a la dispersión de sus posesiones, entre ellas la vivienda a la que nos referimos, que fue comprada y habilitada para uso doméstico familiar.

Seguidamente Ochoa reconoció el capital aportado al matrimonio por su esposa y, en un acto de declaración de amor a su anciana madre, pidió a Clavijo que la cuidara hasta el fin de sus días, dada su avanzada ancianidad y limitaciones físicas. De no llegar a un acuerdo para formalizar dicha tutela, Ochoa ordenó a su esposa que correspondiera a la anciana con un real diario para su manutención.

Finalmente, instituyó como albaceas testamentarios al propio fray Luis, a Blas de Masavel, cantero, y a su cuñado Rodrigo Alonso de Clavijo. Entre los testigos de esta última voluntad del artista, que contaba entonces 52 años, figuraron Pedro de Portichuelo, canónigo de la colegiata de San Hipólito; el citado Blas de Masavel; Juan Gálvez, sastre; y Juan Baltasar de Córdoba, de profesión desconocida ${ }^{14}$.

A partir de aquí el estado de salud del arquitecto se agravó definitivamente y la enfermedad entró en fase irreversible. Solo tres días después de dictar el testamento, Juan de Ochoa falleció en su hogar familiar de la plazuela de don Luis de Godoy, atendido en su lecho de muerte por su esposa y por su madre. Tal como había expresado en la carta testamentaria, pasada la velación, se le dio sepultura en el convento de la Santísima Trinidad, aplicándosele las cien misas en sufragio por su alma.

Días después del entierro, sus albaceas se dispusieron a ejecutar las cláusulas del documento notarial. Con este fin requirieron la presencia del escribano Francisco Rodríguez de la Cruz, quien formuló un extenso memorial con las cantidades detalladas que se le debían al difunto por parte de diferentes entidades y particulares. El texto resulta revelador en muchos aspectos, sobre todo por la cantidad de información que sobre algunas obras desconocidas, aporta al grueso de la producción del artista, como el edificio de la cárcel en la plaza de la Corredera o algunos reparos y conducciones de agua en el convento carmelita de Santa Ana y San José $^{15}$. El documento informa, además, de una deuda de 5000 ducados que el concejo municipal debía al maestro por su obra de la casa de las comedias en la actual calle Velázquez Bosco, hoy Colegio Oficial de Enfermería de la ciudad.

De un modo muy claro y documental, se detalla la obra del maestro en la catedral: "paredes y arbotantes del coro, bobeda, cinborio, arco del testero, posti-

${ }_{14}$ Testamento de Juan de Ochoa, 1 de octubre de 1606, AHPC, Protocolos Notariales, 14774-P, fols. 908-912 vto.

${ }_{15}$ Memorial formulado por Juan de Ochoa con las cantidades adeudadas antes de su muerte, [s. d.], [s. m.], 1606, AHPC, Protocolos Notariales, 15872-P, fols. 286-288. 
gos y arcos del antecoro y los jaspes y piedras duras del altar mayor, postigos y gradas $[\ldots] »^{16}$. Continúa el documento con una cláusula de gran interés:

Yten se me debe el salario de maestro mayor de la yglesia desde el dia que murio Fernan Ruiz en principio de julio hasta 4 dias de octubre que murió Juan de Ochoa son tres meses a rraçon de 4 mrs. cada mes $[. . .]^{17}$.

La cita resulta muy esclarecedora; tras la muerte de Hernán Ruiz III en julio de 1606 en Arcos de la Frontera (Cádiz), el cabildo de la catedral cordobesa nombró a Juan de Ochoa nuevo maestro mayor de sus obras, esperado y feliz cargo que solo pudo disfrutar durante tres meses, al sobrevenirle también la muerte.

Más adelante, el documento informa de una deuda de 100 ducados que el obispo don Pablo de Laguna debía por las tasaciones y reparos llevados a cabo en la hacienda de la Alameda y, por último, también se cita una deuda de 300 ducados que la comunidad de agustinos de la ciudad debía al maestro por la obra en el claustro principal de su convento.

En líneas generales, el contenido del presente memorial ofrece una interesante visión sobre la trayectoria artística de Juan de Ochoa, enumerando algunos de sus principales trabajos y obras al servicio de las principales empresas constructivas del momento.

Finalmente, en una cita al margen, María de Clavijo hizo constar ante el notario las dos cantidades en metálico que su difunto esposo debía: la primera, de cuatrocientos reales, al Ayuntamiento de Écija, en concepto de una multa interpuesta durante el transcurso de la construcción de la citada fuente de las Ninfas; y la otra, de mil reales, a la fábrica parroquial de la localidad de Villanueva de Córdoba. En ambos casos solo se informa de la cantidad adeudada, sin especificar los motivos de las sanciones.

De este modo transcurrió la vida del arquitecto Juan de Ochoa; al servicio de las necesidades del concejo municipal cordobés, muy próximo a las obras de la catedral y colaborando en proyectos de ingeniería hidráulica impulsados por ayuntamientos y comunidades religiosas, entre otras expresiones de su rica personalidad artística. Su buena preparación, eficacia y versatilidad en cuanto a problemas de diseños, reparaciones e informes de conservación no encontraron un fácil sucesor, aunque sí contó con un serio competidor, su propio maestro Hernán Ruiz III. Persona de profunda religiosidad, buena conducta y de entrega constante a su profesión, hemos encontrado en Juan de Ochoa el ejemplo idóneo de "maestro» del siglo Xvi: artista, padre de familia y hombre temeroso de la severidad de Dios. Además, la calidad de sus trabajos, experiencia y confianza en sí mismo fueron virtudes que acompañaron siempre su carácter y le ayudaron a perfeccionar su carrera pro-

${ }_{16}$ Memorial formulado por Juan de Ochoa con las cantidades adeudadas antes de su muerte, [s. d.], [s. m.], 1606, AHPC, Protocolos Notariales, 15872-P, fols. 286-288.

${ }_{17}$ Memorial formulado por Juan de Ochoa con las cantidades adeudadas antes de su muerte, [s. d.], [s. m.], 1606, AHPC, Protocolos Notariales, 15872-P, fols. 286-288. 


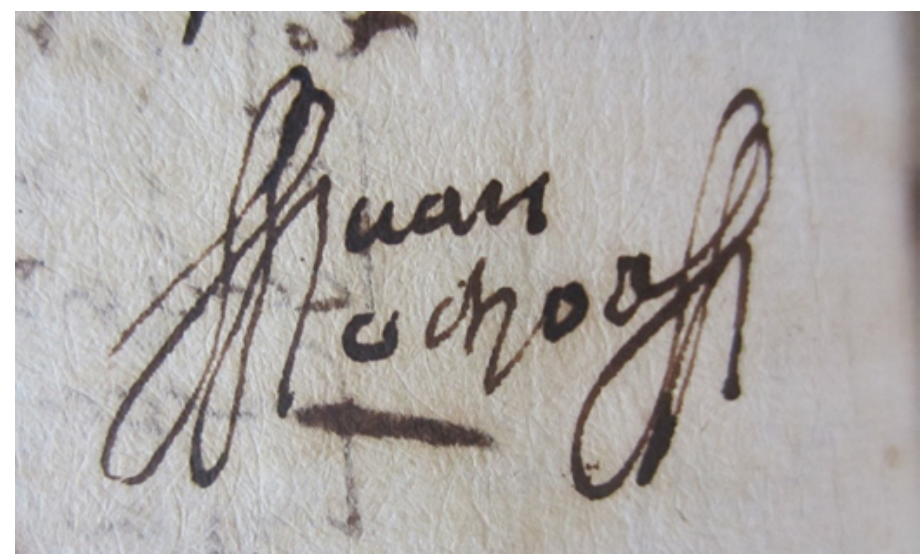

Fig. 7. Rúbrica de Juan de Ochoa en una escritura notarial de 1601.

En: AHPC, Protocolos Notariales, 12428-P, fol. 293 vto. Fotografía del autor.

fesional. Su valiosa e intachable actividad arquitectónica en la Córdoba del último tercio del siglo xvi, el dominio del léxico artístico junto a su faceta de dibujante $y$, sobre todo, sus relaciones con los poderosos mecenas locales del momento han permitido enriquecer la identidad del personaje y definir con mayor exactitud sus perfiles humano y artístico (fig. 7).

ENVIADO: 27 de octubre de 2021; ACEPTADO: 5 de noviembre de 2021 


\section{BIBLIOGRAFÍA}

Banda y Vargas, A. de la (1974). El arquitecto andaluz Hernán Ruiz II. Sevilla: Servicio de Publicaciones de la Universidad.

Camacho Martínez, R. (1986). «Aportaciones al estudio de Hernán Ruiz III». Apotheca, Córdoba: Servicio de Publicaciones de la Universidad, n. 6, pp. 81-94.

Espejo Calatrava, P. (1986). «El patronato de la capilla mayor del convento de Santa Isabel de los Ángeles de Córdoba». Boletín de la Real Academia de Ciencias, Bellas Letras y Nobles Artes de Córdoba, Córdoba: Real Academia de Ciencias, Bellas Letras y Nobles Artes, n. 110, pp. 179-188.

Galera Andreu, P. (2011). «Arquitectos y maestros canteros en Andalucía en el Renacimiento», en Rubio, J. (ed.), Artistas andaluces y artifices del arte andaluz. Sevilla: Publicaciones Comunitarias. pp. 325-366.

García León, G. (1989). «La Fuente de las Ninfas de Écija». Archivo Hispalense, Sevilla: Excma. Diputación Provincial, n. 221, pp. 153-164.

Gómez Bravo, J. (1778). Catálogo de los obispos de Córdoba y breve noticia histórica de su Iglesia Catedral y Obispado. Córdoba: Oficina de don Juan Rodríguez.

Luque Carrillo, J. (2017a). «Aproximación a la figura de Juan de Ochoa: arquitecto e ingeniero hidráulico español del siglo xvi», en Atenea, Santiago (Chile): Servicio de Publicaciones de la Universidad, n. 515, pp. 97-114.

Luque Carrillo, J. (2017b). «La arquitectura del Quinientos en la ciudad de Córdoba (España): antecedentes y principales manifestaciones en tiempos del Inca Garcilaso de la Vega». Revista de critica literaria hispanoamericana, Somerville (EE. UU.): Tufts University, n. 85, pp. 357-378.

Luque Carrillo, J. (2020). El arquitecto Juan de Ochoa. 1554-1606. Córdoba: Excma. Diputación Provincial.

Morales, A.J. (1996). Hernán Ruiz el Joven. Madrid: Akal.

Moreno Cuadro, F. (2009). El Palacio de Viana de Córdoba. El prestigio de coleccionar y exhibir. Córdoba: Publicaciones de la Caja de Ahorros y Monte de Piedad.

Nieto, M. (1986). «La iglesia parroquial de Santaella», en Aranda Doncel, J. (ed.), Santaella: estudios históricos de una villa cordobesa. Montilla: Círculo de labradores de Santaella, pp. 160-196.

Olmedo Sánchez, Y. (2012). «De la ciudad conventual a la ciudad burguesa: las órdenes religiosas en la evolución urbana de Córdoba». Hispania Sacra, Madrid: CSIC, n. LxIv, pp. 29-66.

Rosas, E. (2003). «Hernán Ruiz II, el miembro clave de la dinastía de arquitectos». Arte, arqueología e historia, Córdoba: Asociación Arte, Arqueología e Historia, n. 10, pp. 26-34.

Valverde Madrid, J. (1970). «Juan de Ochoa, el arquitecto de la catedral cordobesa». Revista Omeya, Córdoba: Excma. Diputación Provincial, n. 14, pp. 89-93.

Villar Movellán, A. (1986). «La arquitectura del Quinientos», en Guarinos, M. (ed.), Córdoba y su Provincia, vol. III. Sevilla: Editorial Gever, pp. 209-233. 